\title{
LA RETÓRICA DE LA REPRESIÓN: VIGILAR Y HACINAR EN FUERZAS ESPECIALES DE DAMIELA ELTIT
}

The rhetoric of repression: surveillance and overcrowding in Diamela Eltit's Fuerzas Especiales

\author{
FELIPE ARANCIBIA VENEGAS \\ Universidad de Playa Ancha (Chile) \\ felipe.arancibia@upla.cl
}

\section{Resumen}

Este trabajo analiza el libro Fuerzas Especiales (2013) en cuanto a cómo ciertos elementos claves de la novela, a saber: hacinamiento, pobreza y violencia circunscriben las subjetividades de sus protagonistas generando una inmutable tensión. Se examina el lenguaje utilizado por Eltit en referencia a las figuras retóricas utilizadas y cómo estas constituyen un discurso letal y violento cuya lectura se ve desplazada hacia territorios oscuros e intrincados. Estos territorios son dominados por un Estado cuya esencia se devela por medio de una retórica que es social y políticamente alegorizada por medio de un lenguaje físico y simbólico -la retórica de la represión-que conmina a sus personajes a ser parte de una dialéctica que encarcela y confina sus vidas y almas pero que, de igual forma, abre la posibilidad de resistir estoicamente una ideología segregadora que vigila y restringe todo atisbo de emancipación.

Palabras clave: Hacinamiento; pobreza; violencia; Damiela Eltit; figuras retóricas.

Abstract

This work analyzes the book Fuerzas Especiales (2013) regarding how some specific elements, namely: overcrowding, poverty and violence restrict the subjectivities of the main characters, creating an unchanging tension. Likewise, it examines the language that has been used by Eltit as for the use of rhetorical figures and how these ones make up a deadly discourse whose reading is shifted toward dark and abstruse territories. These territories are dominated by a nation whose essence is unveiled through a rhetoric that socially and politically is allegorized by way of a physic and symbolic language -the rhetoric of repression - that compels its characters to become part of a dialectic that locks up and confines their lives and souls; however, it opens up a possibility to stoically resist a segregating ideology that surveils and limits any glimmer of emancipation.

Key words: Overcrowding; poverty; violence; Damiela Eltit; rhetorical figures

\section{INTRODUCCIÓN}

Dentro de la posmodernidad del relato chileno, Damiela Eltit destaca en virtud de su intento por diferenciarse de otros autores chilenos más dogmáticos. Su literatura, marcada por las ideas filosóficas de Derrida, Marx y Deleuze, se Recibido: 29 agosto, 2019 
erige dentro de un pensamiento deconstructivista: de desencanto social, de luchas de clases y rompimiento de estructuras sociales donde el principal aliciente es el carácter contestatario e irreverente de su narrativa.

Autora de varios libros cuyas génesis están marcadas por el momento histórico de la dictadura chilena, Eltit se erige como una propuesta de literatura chilena que rompe la censura de un discurso marcado por la mano estatal $/ \mathrm{militar}$ que se ha caracterizado por su violencia y disyunción. Esta censura militarizada, en conjunto con los fantasmas que esta dejó, abre una nueva posibilidad de escritura: un relato social, político y estético cuyo corolario es el contradiscurso que surge desde la marginalidad de una sociedad chilena sometida a una ideología brutal. De este modo, surgen libros y relatos como Lumpérica (1983); El Padre Mío (1989); Vaca Sagrada (1991); Mano de Obra (2002) e Impuesto a la Carne (2010), entre otros, cuyos rasgos más trascendentales apuntan a una crítica severa contra del Poder y el Estado, exteriorizando los crudos detalles de la marginalidad y la injusticia social. Asimismo, Eltit intenta, en su narrativa, revelar aquel sujeto -con especial énfasis en el femenino- que divaga dentro de un paradigma segregador y clasista, cuyo cuerpo y lenguaje son sometidos a la constante violencia física y epistémica que emana de un arquetipo social que domina, asola y atraviesa los cuerpos y las almas de sus sujetos.

Dentro de esta literatura, nace Fuerzas Especiales (2013), una de las últimas obras de Eltit. Fuerzas Especiales sobresale por su escritura marcada por la sequedad en cada una de sus oraciones, de un vocabulario frío e indocto que en ocasiones duplica el diálogo callejero, fortuito y ocioso que gobierna las poblaciones marginales. En este contexto relegado, la violencia física e ideológica aparece como el principal aliciente que asoma en cada línea, como si estas simbolizaran las calles donde las turbas nocturnas que rigen estas vías aparecen: edificaciones de paredes opacas, calles sucias y agrietadas donde sus habitantes pasan sus días y años viendo cómo aquella maquinación muy bien urdida segrega sus destinos y sus subjetividades, confinándolas a ser presidiarios en un mundo que propone una libertad camuflada:

Yo sé que a mi padre ya le cuesta demasiado el bloque y que no puede enfrentarlo como antes, que sus costillas quebradas lo demolieron, que las busca en sus sueños y que cuando se ve en el espejo no entiende qué ha pasado en su cara y piensa que, en cualquier instante, mientras se mira en el espejo, va a aparecer a su lado la cara de un tira (Eltit, 2013, p. 106)

Damiela Eltit forja este relato de manera inteligente donde los recursos disponibles a nivel lingüístico -gramaticales, retóricos y estilísticos- son debidamente acomodados por la escritora con el fin de exhibir una narrativa de 12 | AlPHa No 52 (Julio 2021) PÁGS. 11-30. ISSN 07 16-4254 
personajes anónimos y de diálogos sandios cuya justificación es la inquietante carga de marginalidad y pobreza que atraviesa a cada uno de los copartícipes de esta narrativa: "[...] Me gustaría llamar al Omar o al Lucho pero no tengo un peso en el celular, no tengo un peso en ningún recodo de mi cuerpo, no tengo un peso en los pliegues de mi mochila, ni un peso en el hueco de la pared del departamento" (Eltit, 2013, p. 43).

La estructuración de cada uno de los capítulos de Fuerzas Especiales es cimentada por párrafos excesivamente largos donde los renglones del texto se apoderan del campo visual del lector. Eltit, en una movida estratégica e indispensable -propia de las "Fuerzas Especiales"- narra su ficción bajo ese parámetro de observación y observancia. De este modo, el lector es acorralado en el amontonamiento que la propia lectura suministra: una escritura hacinada, con pocos espacios, sinuosa y de pocos intersticios; una escritura densa y comprimida que busca arrimo en el báculo que merodea cada esquina de aquella población desconocida para el lector.

En esta retórica discursiva que se torna pesada e intransigente, la autora advierte el constreñimiento propio de un sistema oculto y perverso. De este modo, las figuras retóricas se convierten en aquellas patrullas que mantienen a los habitantes de estas poblaciones callampas en perpetua vigilancia. Es el panóptico que Eltit erige y que va desde principio a fin, o que más bien crea una muralla ficticia y metaforizada que rodea -sin aparente discernimiento por parte de los habitantes/personajes de la historia- los bloques segregados de norte a sur, de este a poniente; día y noche, veinticuatro horas.

En esta propuesta escritural Eltit denuncia -como uno de los pilares fundamentales del libro- las formas represivas (provenientes del control policial militarizado) que constantemente mantienen a raya a los ciudadanos marginados de una sociedad que, dentro del paradigma actual de mercado, se convierten en un estorbo que rápidamente hay que eliminar:

Ellos, los policías, nos siguen por todas partes, nos estudian porque formamos parte de su trabajo, lo sé. Hay que cuidarse siempre de los tiras, por eso mi mamá está tan pendiente de mi hermana, de mi papá, de ella misma, de mí, porque teme que la policía que sirve a la metalización del mundo nos quiebre y nos disuelva como a esa parte de la familia que no debemos nombrar. Mi mamá piensa, y yo también pienso igual que ella, que podríamos disgregarnos hasta no formar parte de nada en el universo (Eltit, 2013, p. 26).

De este modo, dentro de este contexto alegóricamente carcelario se instituye Fuerzas Especiales: una mujer desconocida que divaga entre pasajes angostos y bloques de un cemento de mala calidad que relata -en primera 
persona- la vida de ella, su familia y sus "amigos"; una vida desesperanzada que transcurre lánguidamente, sin rumbo, bajo un discurso letal y violento que se entrecruza con la vida de muchos ciudadanos segregados que deambulan entre las paredes de un sistema impertérrito que no les entrega respuestas.

\section{TÁCTICA I: HACINAMIENTO Y SEGREGACIÓN}

Fuerzas especiales es un libro complejo. Tras las pocas pistas que su autora esboza en las calles de la población, se desprende la primera lectura: que el contexto físico-espacial donde se inscribe esta historia, el de la "población callampa" y sus significantes principales como el hacinamiento, la segregación, junto con la mala calidad de las construcciones genera una constante tensión entre sus personajes que se expande física y alegóricamente por todo el libro. Esto podría leerse como la primera de las estrategias que el poder -resguardado por las Fuerzas Especiales- pone en práctica para controlar a los personajes/habitantes del libro. Respecto del fenómeno de la población callampa, Gómez Leyton aclara lo siguiente:

[...] Las poblaciones "callampas" fueron, durante esas décadas, la expresión del asentamiento urbano de los sectores populares excluidos del mercado capitalista de la vivienda. Ellas se constituyen a partir de la movilización social de los sectores populares "sin casa" e imposibilitados de participar en el mercado habitacional debido a sus escasos recursos económicos (Gomez Leyton, 2018, p. 5).

Esta puesta en escena de Eltit es la cruel puerta de entrada para la lectura de Fuerzas Especiales. El contexto "callampa" que plantea Gómez Leyton establece una correspondencia indisoluble entre los factores pobreza y vivienda que se observan en el relato. Los desplazamientos semánticos que dominan los diálogos que se forjan entre los personajes van confrontando las murallas de los bloques con las propias experiencias de sus habitantes, las que van desnudando estos estados alterados de conciencia que se leen, por ejemplo, cuando el Omar-uno de los amigos de la anónima narradora-vislumbra la mísera construcción en la que él habita:

El Omar mira detenidamente los pasillos de cada piso. Los evalúa y los mide con un ojo demasiado demoledor. Jamás descansa su malestar. Piensa en su piso, lo sé. Piensa que su bloque es lo peor, piensa que cambiaría su bloque por el mío. Piensa que él se merece mi bloque. Piensa que es un condenado por el espacio. Eso lo desespera. Le destruye parte de la vida que su bloque esté a punto de colapsar debido al peso creciente de las rejas oxidadas (Eltit, 2013, p. 62). 
Uno de los mensajes más importantes que la autora intenta dar cuenta es el hecho que existe un comando central, un Poder que patrocina el señorío de su propia casta social poderosa e invisible, por sobre otra -la débil- condenando a un sector de ciudadanos a vivir en ghettos, desplazando a los habitantes fuera del territorio capitalista. Estos métodos ayudarían a mantener al ganado social dentro de la guarida: amontonado y, en consecuencia, pobre. Esta mezcla de pobreza, que se funde con otros elementos significativos del libro como la violencia y el miedo, dan cuenta del crudo existir de una parte de la población que vacila entre el asedio de la policía y las vías de escape que el mismo sistema proporciona:

Por eso están enfurecidos los policías, porque no mataron a nadie hoy y expresan su odio con palabras defectuosas, mientras los niños más afiebrados de nuestro bloque festejan los golpes con sus desafinadas carcajadas y afirman que quieren ser policías mientras describen los bordes de los cascos y alaban las botas, las hebillas, la fortaleza plástica de los escudos, y se abrazan al cemento de mala calidad (Eltit, 2013, p. 39).

Para entender la propuesta de Eltit en este primer análisis, se debe ahondar en la relación de los elementos claves hasta ahora propuestos. Por tanto, resulta importante establecer una correspondencia entre las piezas de este acertijo: el binomio segregación/hacinamiento y la pobreza que desborda los habitantes anónimos de los bloques. Al respecto, Castells entiende la segregación urbana del siguiente modo:

[...] [la] distribución de los lugares de residencia [que] sigue las leyes generales de la distribución de los productos y, por tanto, produce reagrupaciones en función de la capacidad social de los sujetos, o sea, en el sistema capitalista, en función de sus rentas, de su estatuto profesional, del nivel de instrucción [...] (Castells, 2004, p. 203).

En esta hegemonía capitalista y neoliberal de mercado que envuelve a Fuerzas Especiales, se entiende que uno de los pilares fundamentales para respaldar este modelo de mercado es la aniquilación del adversario que no cumpla con los cánones mencionados por el autor. De este modo, se sustenta la hipótesis en donde la condición pobre de los personajes del libro los confina en lugares desplazados de la centralidad en donde prima el hacinamiento y la segregación. Así lo establece Portillo (2002), quien propone una relación entre capitalismo y segregación que resulta importante para esta investigación: “[...] el propio sistema capitalista se convierte en cada vez más excluyente y segregador, desde el punto de vista social, poniendo de relieve no solamente sus contradicciones sino [que] su carácter depredatorio de la especie humana [...]" (Portillo, 2002, p. 44). 
Es importante recalcar que los significantes que conforman el carácter depredatorio del capitalismo -exclusión y segregación, entre otros- son reveladores para transitar las calles del libro. En estos se hallan los preceptos de un aparato estatal militarizado que desborda violencia y subordinación; exterminio y represión. Una máquina cuyo(s) jefe(s) operador(es) permanecen en el más completo anonimato, eternizando así un sistema capitalista que se instituye como devastador y, por esta razón, violento e implacable:

Mi padre se desvela de manera obligada cada noche. Como un acucioso guardián nocturno, se da vueltas y vueltas en su cama mientras espera a la policía o evita soñar con el lumazo, el que le dieron en su costado y le hizo polvo dos costillas. Dos de sus costillas derechas. Desde aquel día quedó medio chueco mi papá, desnivelado, porque estaba en la calle, caminando al lado de uno de los bloques más distantes, parado afuera cuando los carabineros llegaron repartiendo lumazos justo el día en que estaban recién pagados. Llegaron corriendo con sus bototos estatales [...] (Eltit, 2013, pp. 49-50).

Este escuadrón estatal militarizado -que de manera perpetua y transversal acosa y asedia a los habitantes de la narrativa- se erige como un grupo oscuro e inhumano que arremete sin piedad contra los habitantes del libro: "[...] todavía nos mantenemos en pie como familia debido a un montón de artimañas peligrosas que nos van a terminar por destruir cuando nos invada la policía" (Eltit, 2013, pp. 32-33). Sin embargo, la autora no traza líneas explícitas de la procedencia de este grupo nacional armado. Hallar la respuesta, por tanto, se convierte en una ardua tarea para el lector. Sin embargo, existen pistas sutiles que arroja la autora, las que invitan al análisis más fino. En el extracto anterior se sugiere, por ejemplo, una lectura que podría dejar rastros en cuanto a la procedencia de esta guardia armada que protege a este "Estado/Poder Oculto". En la frase el lumazo que hizo polvo las dos costillas derechas, se entregan indicios relevantes para interpretar la procedencia de este grupo. La escritora aludiría, en el castigo corporal sufrido por el padre de la narradora, al flanco de "Derecha del Poder" que en Chile contó con el respaldo de las Fuerzas Armadas. Así lo sugiere Etchepare en su artículo pertinente a las Corrientes Ideológicas de Derecha: "La derecha política prestó su adhesión irrestricta al Pronunciamiento Militar del 11 de septiembre de 1973 [...]" (Etchepare, 2018, p. 8).

Una de las lecturas de Fuerzas Especiales proyecta un intento desesperado de Eltit de apuntar con el dedo a aquellos conglomerados políticos que han mantenido fuera del territorio productivo a las clases bajas de este país. Asimismo, la escritora deja entrever en la frase anterior "los bototos estatales", 
cómo esta conexión entre las Fuerzas Armadas y el Poder se extiende en el tiempo, prolongándola al contexto actual donde Fuerzas Especiales acontece.

Precisamente, y para sostener esta hipótesis, acudo a Rubio quien expresa en su artículo acerca de la Política chilena y la Derecha, que hubo un ánimo de extender esta ideología - por parte de las FFAA- hasta los tiempos actuales: "Si bien Augusto Pinochet mostró agradecimiento por el apoyo brindado por este sector de la política chilena [la derecha tradicional], este mostró preferencia por los 'gremialistas' y por los tecnócratas-economistas, con lo cual potenció un sector de la derecha que después se fortaleció aún más, proyectándose incluso al período democrático" (Rubio, 2018, p. 10).

La predilección de los grupos chilenos de derecha militarizada hacia la tecnocratización del país sustentaría el binomio político/ideológico que, oculto y protegido, tramaría sus regímenes oscuros cuyos criterios circunscriben las libertades físico-espaciales de los sujetos/personajes de este libro. De igual forma, se observa un aislamiento espiritual que trasunta en la condición angustiante del personaje subyugado de Fuerzas Especiales al enfrentar el yo/arrojado-al-mundo con el yo/ser: esta incapacidad de actuar, sentir y pensar que se ve patrocinada por una imposibilidad de acero que refrena todo afán de emancipación física y emocional del habitante de la población. Esta idea podría leerse como aquel vacío existencial que el habitante del bloque experimenta ante cualquiera de sus posibilidades, limitadas por las condiciones de juego que impone el Poder. Así lo plantea Kierkegaard en El concepto de la angustia: “¿Qué es entonces lo que hay? Precisamente eso: ¡nada! Y ¿qué efectos tiene la nada? La nada engendra angustia. El espíritu, soñando, proyecta su propia realidad, pero esta realidad es nada [...]" (Kierkegaard, 2007, p. 22). Esta idea reveladora puede ser observable en el diálogo en donde el Omar, el Lucho y la narradora conversaban dentro del ciber:

El Omar, el Lucho y yo tenemos la misma edad: mismo mes, mismo día, mismo año. Lo que nos diferencia es el bloque y esa distancia nos da otras perspectivas. Nos separan tres cuadras. Juntos sumamos tres bloques. Cuando el Omar va a mi bloque reconozco en su mirada la desolación. Un vacío que le clausura cualquier forma de optimismo (Eltit, 2013, p. 61).

Por tanto, Fuerzas Especiales podría concebirse como un libro existencialista en cuanto sus diálogos frívolos van pavimentando cuestiones trascendentales que ayudan al lector a entender esta intrincada novela. Más aún, la dialéctica que constantemente se genera entre sus personajes trae a colación lo que Sartre denomina la trascendencia negativa, la que apunta a un ser humano constituido por/en su propia incertidumbre. Esto queda de manifiesto cuando el filósofo, en una de sus preguntas trascendentales, reflexiona lo siguiente: “¿Qué 
ha de ser la conciencia en su ser para que el hombre en ella y a partir de ella surja en el mundo como el ser que es su propia nada y por quien la nada viene al mundo? (Sartre, 2005, p. 93).

Necesariamente, el habitante de Fuerzas Especiales exhibe un inmutable vacío espiritual - una nada- que atraviesa todo el libro. Lo iterativo de una vida insípida, sumado a la ideología de mercado y al hacinamiento físico e ideológico, va erigiendo una narrativa que, de manera contundente, exterioriza las graves consecuencias que esta doctrina ha causado en los personajes del libro: "[somos] manadas de gatos muertos de hambre [...]" (Eltit, 2013, p.15). De este modo, esta intrincada promiscuidad de elementos va sugiriendo un camino oscuro y serpenteante con el que Eltit intenta dar a conocer su mensaje a una parte importante de la sociedad que ha sido anulada y mutilada. Precisamente así lo señala Mayol en su ensayo de la tecnocracia y sus efectos en la sociedad:

En este discurso tecnocrático (pero no sólo discurso) está la promesa de una política unívoca, definitiva, incuestionable y operacionalizable, la promesa de que el sentido de la historia encuentra en la razón técnica la orientación fundamental. Sin embargo, la tecnocracia no parece ser sino lo contrario a una orientación fundamental, siendo otra forma más de la pérdida del sentido y de la libertad que Weber detectaba como una jaula de hierro hacia donde iba la racionalidad en el capitalismo. Es así como la tecnocratización sólo puede desenvolverse en tanto anulación de la posibilidad de que sean los hombres los que construyan su historia (Mayol, 2003, pp. 1-2).

La cita anterior es clave para entender la narrativa de Eltit: el apoyo de este grupo violento militarizado -que Eltit exacerba en su narrativa- brinda apoyo irrestricto al Estado capitalista/tecnocratizado. Este, en su concepción de oferta y demanda, de intercambio y transacción, arrastra al sujeto a la fase de "petrificación mecanizada" que menciona Weber en Mayol, la que desplazaría las subjetividades de todos los habitantes de Fuerzas Especiales un estado de alienación total que se observa en la histeria, la obsesión y la disociación cuerpo/mente de los habitantes de los bloques. Este argumento se sustenta cuando la narradora observa a su "amigo", el Lucho, mientras ambos dialogan de manera circunstancial en alguna esquina desconocida: "[...] el Lucho no le habla porque está pensando en otras cosas, está ausente el Lucho y no sé qué le preocupa o qué planes está poniendo en marcha en su cabeza, pero, aunque está totalmente ido, nos sonríe [...]" (Eltit, 2013, p. 108).

La alienación, como flujo descodificado, se entiende como todos los códigos de vida que son propiedad de los sujetos-capitalistas; esto, en Fuerzas 
Especiales podría leerse, entonces, como aquella disección administrada por la "Máquina Despótica" (y manejada por hombres/cuerpos/órganos) cuyo propósito es sobrecodificar y perpetuar la unidad estructural de la máquina que mantiene en funcionamiento tal entramado; así como lo propone Butler y que Deleuze trae a colación: "Las máquinas prolongan el organismo [...] miembros y órganos yaciendo sobre el cuerpo sin órganos de la sociedad, que los hombres se apropian según su poder y su riqueza, y de los que la pobreza les priva como si fuesen organismos mutilados" (Deleuze, 1985, p. 131). De esta manera, todo atisbo de libertad física y espiritual queda atrapado en esta máquina nociva que podría denominarse como "la nueva ideología de racionalización capitalista", donde el Poder es completamente ejercido por sujetos sin espíritu e inmorales. Esta mutilación de los cuerpos/mentes, observada en los personajes/habitantes, queda en evidencia cuando, por ejemplo, la narradora -mientras observa a su hermana ver en la televisión un documental cuyo título era "La pasión mutante de la crisálida"- se explaya por el giro que pretende dar en su vida desafortunada: “[...] nos dice también que sus ojos se habían separado de su cuerpo y que, desde un lugar estratégico, le miraban la espalda no con lástima, sino más bien con curiosidad" (Eltit, 2013, p. 75). Al final de aquel diálogo, la hermana (cuyo nombre nunca aparece en escena) define a aquel documental como "un ejemplo de superación para el conjunto más opaco de la humanidad". Este antieufemismo (al referirse la hermana a ellos mismos como "el conjunto más opaco de la humanidad") arroja luces en aquel constructo: considerando el argumento de Deleuze en donde el despotismo se pone al servicio de la nueva relación de clases (p. 225), no existiría manera de sobrecodificar los códigos ni los mismos habitantes/personajes desterritorializados; por tanto, la metáfora deleuziana: " Vosotros, griegos, nunca dejaréis de ser niños"” (p. 225) se podría leer del siguiente modo: "Vosotros, pobres, nunca dejaréis de ser pobres".

La imposibilidad de hierro metonimizada en la jaula manifiesta la rigidez, la dureza y la inflexibilidad con que los tecnócratas -cuya protección es suministrada por las Fuerzas Especiales - van pavimentando las calles en esta narrativa. Esta imposibilidad se alza como un calabozo que se desplaza hacia territorios cada vez más oscuros; territorios desplazados por metáforas y metonimias complejas que el lector debe ir descifrando en el camino. Esta doctrina letalmente simbolizada, que se expande de forma devastadora, es insinuada por Eltit en uno de sus capítulos, cuando la hermana y su madre mantienen una acalorada discusión entre cuatro paredes:

Las cuatro paredes atravesadas por la afilada peineta, los gritos de mi hermana azotándose la cabeza contra las exactas cuatro paredes. Con la frente rota por los golpes mientras que mi madre las emprendía en contra 
de ese pelo ayudada por la sangre que estaba allí para humedecer y reafirmar el rígido peinado que mi hermana no soportaba porque quería el pelo suelto, muy negro y suelto para escamotear su cara del espejo o rehuir la violencia de las miradas. Un pelo que mi madre, la nuestra, nunca pudo soportar ni menos comprender, porque ella, nuestra madre, no tuvo la oportunidad de pensar el rostro como de los problemas más agudos que mi hermana se negaba a enfrentar. Los golpes, su pelo endurecido por la densidad de la sangre, la calle, el silencio entre nosotras, la molestia que yo les provocaba a ambas cuando me convertía en una desapasionada testigo (Eltit, 2013, p. 31).

Los elementos aludidos por Eltit en este párrafo simbolizan -de manera notable, creo- el auge del capitalismo en todo su esplendor: las cuatro paredes, metonimia de la jaula de hierro, que restringe a los personajes/habitantes de manera física y espiritual; la madre, una mujer atravesada por un discurso estatal cuyo cuerpo dócil ha sido moldeado para servir a la superestructura; la sangre, cuya lectura aludiría al componente más básico del ser humano cuya pureza ha sido mancillada por el discurso tecnocapitalista, dejando su marca en los cuerpos de los personajes/habitantes de Fuerzas Especiales; finalmente, el pelo, cuya simbología apela al crecimiento desenfrenado de la ideología de mercado; capitalismo que crece en todas direcciones, en todos los rumbos; pelo que cubre los ojos de millones de personas; una ideología que enceguece y no permite leer la realidad de las cosas.

En este primer análisis, se da cuenta de cómo la segregación y el hacinamiento han implantado los límites del espacio que habita el sujeto de Fuerzas Especiales. Este espacio se encuentra cercado por una barrera imperceptible, metonimizada por una ideología de mercado, tecnocapitalista, cuyos ejes, hasta ahora -segregación y hacinamiento-, van afectando negativamente las subjetividades de los personajes del libro. La idea más importante que se rescata en esta primera parte, es el hecho que existe una doctrina desalmada, que, avalada por el Estado, constriñe a un sector de la población y los priva de un derecho fundamental cual es la vivienda y su consiguiente privacidad/espacio. Se observa, del mismo modo, un apremio físicoespacial tan letal que incluso los personajes aludidos en este primer nivel de análisis bordean, varios de ellos, la locura, que se exterioriza en cada intervención. Asimismo, esta enajenación es observada cada vez que la narradora ahonda en la correlación vivienda/miedo: "[...] me da pánico que el paco, un oficial que vi en la tarde, el más alto de todos, el que tiene una calvicie avanzada, entre al departamento y mi hermana se ría de él. Se ría de miedo o se ría porque quiere que la maten [...]" (Eltit, 2013, p. 115). 


\section{TÁCTICA II: POBREZA Y ESCASEZ}

La lectura principal que Eltit ofrece en Fuerzas especiales es -hasta ahorala revelación de un plan oscuro e intrincado que, concebido por manos que escapan a la lectura misma del libro - pero que atisban conexiones a nivel políticotecnológicos-buscaría mantener a las clases bajas en un inmutable y brutal cautiverio físico y mental. Sin embargo, el lector no solo debe leer este cautiverio/segregación de forma literal en relación con lo espacio-social. Fuerzas Especiales es un libro donde otro fenómeno es observable: la pobreza que envuelve el relato. Es un campo complejo de analizar porque el concepto en sí mismo abre otros niveles de significados que atraviesan ámbitos como lo filosófico, lo político y lo económico. Es por esto que resulta necesario proveer cierto contexto desde el fenómeno de la pobreza en Chile para poder establecer algunas relaciones que son cruciales para leer a Fuerzas Especiales:

[...] Chile sigue siendo un país que presenta un elevado nivel de desigualdad en la comparación internacional. En el país hay grupos de la población que acceden a niveles de bienestar que son propios de los países más desarrollados mientras que otros viven en condiciones de pobreza y marginalidad; entre estos extremos hay una clase media relativamente acomodada y que ha crecido en los últimos años, pero también hay una clase media baja cuyos niveles de ingresos son precarios y que viven sujetos a incertidumbres y vulnerabilidades en lo económico (Larrañaga y Rodríguez, 2018, p. 33).

Esta incertidumbre y vulnerabilidad que señalan Larrañaga y Rodríguez es observada en varios pasajes del libro. El invariable devenir de sus personajes revela las grietas de un grupo de habitantes que se arroja al mundo como el segmento más miserable de la sociedad. Entre ellos, entablan analogías denigrantes e ignominiosas que revelan el crudo existir de esta parte de la población que se constituye a sí misma bajo metáforas que flagelan sus mentes y que alegorizan a una sociedad cruel que se construye desde el paradigma de lo desalmado y chauvinista:

Deseo que mi risa atraviese el bloque para distribuir de manera más justa este insomnio que me impulsa a recordar el baile del sitio brasileño que celebraba la música y las lágrimas impresas en los movimientos de los antiguos esclavos. Los mismos esclavos que viajaron por barco, posiblemente encadenados [...] viaje esclavo que, según ellos, los testigos, había traído la música que se extendió junto con las epidemias por el nuevo mundo (Eltit, 2013, 41-42). 
La alusión al esclavo que se lee en el párrafo anterior permite al lector codificar el vacío y la desesperanza que gobierna a los personajes de Fuerzas Especiales. La carga semántica de esta palabra va forjando en el entorno de los personajes un contexto mezquino y exiguo que se apodera de los personajes principales que conviven inexorablemente con el flagelo de la persecución ideológica y policial. Dentro de esta acechanza, los habitantes de los bloques deben huir como ratas que sortean a sus depredadores. Un juego letal, una semiosis disgregada, un discurso indigente que lleva a la narradora a introducirse en un estado onírico que relata del siguiente modo:

Dice que en el sueño pensaba en mí y trataba de protegerme de las oleadas tóxicas que emanaban de la rata. Dice que era una rata tecnológica y formaba parte de una nueva experiencia de caza, que estaba allí para transmitir una forma de infección masiva que liquidaría a los bloques. Dice que después de la rata aparecía una proyección digital en un compacto plagado de noticias ininteligibles que eran emitidas en una lengua nórdica (Eltit, 2013, p. 95).

No obstante, las asignaciones de significados van más allá en Fuerzas Especiales. Eltit -de manera constante- deja entrever representaciones que son intrínsecamente asociadas al fenómeno de la pobreza y la escasez: "mi madre distribuyó el pan [...] teníamos la misma hambre, idéntica angustia ante los panes. Comíamos apresuradas y nuestra hambre se consumó en el pan, mientras mi madre nos decía con la boca llena de migas: va y vuelve [...]" (Eltit, 2013, p. 55). La inestable fluctuación económica que carcome los bolsillos de la población de Eltit trae a la superficie temas comunes como el hambre y la angustia. En esta dialéctica miserable, se genera un desasosiego existencial que se lee como aquella demanda por las necesidades básicas que escasean en cada párrafo del libro: "[...]cuando entre al departamento me dirá con una voz desgastada, cruzado por un matiz de desorden y de confusión: y tú, qué andai haciendo en la calle, que no te dai cuenta que tenimos hambre" (p. 27).

Del mismo modo, se observa cómo Elit intenta deconstruir la imagen patriarcal del proveedor, al situar al padre de la narradora como un personaje pobre, pero también violento: "Pude presagiar los gritos, los insultos, los golpes y el desconsuelo de mi papá ante su caja de vino vacía [...]" (p. 57). De este modo, la violencia por parte del padre desplaza los significantes hacia otro ámbito importante: abre la posibilidad de analizar el fenómeno de la pobreza desde el ángulo de Nación. Por ejemplo, Eltit acomete con la metonimia del padre, en la que se relaciona la figura del hogar de la narradora con la figura del signo Estado. De esta manera, se podría hacer la lectura del padre/país, como un agenciamiento 
en donde las necesidades básicas no son cubiertas, y, más aún, son negadas por medio de las líneas de fuga que proyectan violencia y miseria. Es una alusión significativa por parte de la autora, que provee conexiones intrincadas y oscuras, pero que develan el actuar de las Superestructuras del País, la que concluye que las políticas exhiben los abusos económicos de la Máquina Estatal, dominada por el falocentrismo que Eltit subraya en sus argumentos.

Lo curioso de Eltit en el relato de Fuerzas Especiales es el hecho que sus argumentos devienen continuamente de forma ilógica. En esta lectura intrincada e impredecible, la autora arroja pistas contundentes de cómo las doctrinas que dominan la sociedad generan discursos de poder que son ambiguos y poco claros, los que Eltit analogiza en su discurso: "Aparecieron tal como son, iguales a ellos mismos, consumidos por el borde opaco de una extensa belleza. Misteriosos. Ni sanos ni enfermos" (Eltit, 2013, p. 17). La autora genera alusiones y metáforas que apuntan a la antítesis del discurso de Estado. En esta dualidad discursiva, el lector -de manera incesante- se ve atrapado en estos cortes de flujos que revelan una narrativa paradójica e incongruente. Apunta a lo que Derrida se cuestiona en La escritura y la diferencia: "¿Cómo transgredir a la vez lo mediato y lo inmediato? [...]" (Derrida, 1989, p. 376). De hecho, Derrida escribe que "la neutralidad del discurso tiene una esencia negativa" (p. 376). El francés encauza la destrucción del discurso como: "Aquella [que] multiplica las palabras, las precipita unas con otras, las sume también en una sustitución sin fin ni fondo, cuya regla es la afirmación soberana del juego al margen del sentido [...] (pp. 377-378). De hecho, se puede citar el párrafo a continuación, el que apoya esta idea, en el momento que la autora califica a los policías de "pájaros hambrientos", abriendo las infinitas posibilidades de significación, dentro del marco bizarro y caótico que provee la semiosis misma de la narrativa de Eltit:

Los tres miramos desde el cuarto piso los movimientos policiales. Estamos apoyados en la baranda que mejor conozco. Desde arriba, los policías se ven como una producción animada, porque los uniformes de los pacos tienen trazos firmes que alardean su supremacía. Un estilo copiado de una bandada de pájaros hambrientos. Eso lo hablamos largamente el Omar, el Lucho y yo la noche que nos comimos unos completos (Eltit, 2013, p. 68).

Dentro de este marco de significación, se va erigiendo la riqueza discursiva de Eltit que se contrapone con la pobreza del relato. Esto lleva a examinar y discutir conceptos clave como son la libertad, la justicia y la riqueza, los que son enérgicamente cuestionados por medio de figuras retóricas que Eltit expone de manera iterativa. Este cuestionamiento alude a lo que establece Marcuse, en cuanto a la relación civilización/tecnocracia y el auge de ella, y que Eltit intenta 
exasperadamente oponerse y redimirse: “[...] la pobreza, la enfermedad y el crecimiento canceroso son males tanto naturales como humanos: su reducción y anulación es liberación vital [...]" (Marcuse, 1968, p. 122). De este modo, son las analogías, la paradojas, los paralelismos y las metáforas, entre otros, las que van promoviendo un estado fenomenológico de conciencia y reflexión hacia el lector que se manifiesta en la carencia -tanto monetaria como espiritual-que el mismo relato simboliza; una estrategia cuya fase inicial es la abstracción de sus protagonistas que son conscientes de los efectos político/históricos de una genealogía adversa y un pragmatismo apremiante que conmina a sus habitantes/personajes a vivir bajo las premisas de un Poder que impone sus propios conceptos de equidad y libertad; una dialéctica cuyo contradiscurso se manifiesta como una pulsión llena de escasez, paranoia y rencor:

Estamos en el cíber y tenemos hambre, los tres. Tenemos hambre y nostalgia, hambre y miedo, hambre y temor ante la posibilidad de que lo poco que queda se venga abajo pero todavía nos queda una forma curiosa de odio profundo, incisivo, sin el menor atisbo de remordimiento (Eltit, 2013, p. 151).

\section{TÁCTICA III: LOS APARATOS DEL MIEDO}

Fuerzas Especiales se construye bajo el alero de la ideología capitalista. Esta se convierte en el armazón que moldea aquella población vigilada y segregada: los grupos económicos de dominio son los ingenieros y arquitectos que forjan y parcelan los territorios urbanos. Una partición física, económica y social que arremete violentamente en los cuerpos de los personajes/habitantes de Fuerzas Especiales. Este grupo dominante que compone y organiza el Estado funda y nutre los aparatos del miedo especializados en vigilancia y represión, como los pacos y los tiras que se mencionan en el libro. Así lo plantea Althusser, en su estudio de los aparatos ideológicos del Estado: “[...] El estado es concebido explícitamente como aparato represivo. El estado es una 'máquina' de represión que permite a las clases dominantes [...] asegurar su dominación sobre la clase obrera para someterla al proceso de extorsión [...]" (Altusser, 1988, p. 19).

Esta empresa ideológicamente bien urdida, y que se configura tras el soporte de una economía/política centralizada y a la vez desconocida para los habitantes/personajes de los bloques no solamente planifica las tácticas de hacinamiento y de pobreza que se manifiestan en el libro. Igualmente, este aparataje lubrica otros engranajes que el Poder ensambla perspicazmente y despliega tras sus infinitas cadenas de soporte: una escuela que se viste de policía que -mediante sus prácticas violentas e intransigentes- se va alimentando con las 
carnes y el miedo de los personajes/habitantes del libro. De este modo, el Poder en Fuerzas... extermina a una parte olvidada de la sociedad que observa al mundo tras ventanas de plástico y techos oxidados por el miedo y la miseria:

No contamos con un solo peso, o, si lo tenemos, no nos alcanza para nuestros consumos y menos para los ocasionales excesos que nos permitimos. Hoy decidieron no vaciar los bloques. No los vacían porque es un operativo blando, inofensivo. ¿Cómo lo sabemos? Por los números de tanquetas, las balizas, las bombas de gas, los cascos, los garrotes, los gritos, los carros lanzaguas [...] (Eltit, 2013, p. 66).

La tensión que imprime las Fuerzas Especiales en los personajes del libro se instituye como la metonimia de una escuela macabra. Esta doctrina, que parte por los ensamblajes de apoyo del Estado, inscribe en el cuerpo de los sujetos su designio: ultrajar, subordinar y reducir al grupo más olvidado de la sociedad. Este grupo subsiste bajo la reclusión carcelaria de sus hogares, la locura y la violencia por parte de los aparatos del Poder y el relieve oscuro e ilegal de su topografía. Todo esto va conformando un modo de vida cuyos criterios moldean tanto los bloques como las vidas de los personajes/sujetos del libro. Este camino sinuoso y curvado deja una huella latente en el actuar de los personajes, el que deviene entre la hegemonía dominante y socialmente aceptada por el Estado y las prácticas que ellos exhiben dentro de la población.

Por medio de códigos sociales, edificaciones de bajo presupuesto y discursos violentos que los brazos articulados del Estado ponen en marcha, se va produciendo una escisión social y psicológica del sujeto/habitante de Fuerzas Especiales. Esto genera un discurso segregacionista cuya consecuencia es la tipificación del sujeto/personaje que se confina al "banquillo de los acusados", cuyos jueces morales (el Estado) generan contradiscursos que "metaforizan" el sedicioso carácter de su actuar; son los personajes/habitantes de Fuerzas Especiales los que sirven al Estado para sustentar la noción del signo "criminalidad". Estas tácticas/estrategias cuya naturaleza psíquica-que apunta al alma del individuo- estarían sujetas aparentemente a lo que Zizek (2009) denomina como la biolpolítica pospolítica. Esta afirma que hoy existe una renuncia a la causa ideológica, siendo su resultado la "eficiente administración de la vida" (p. 55). Esta administración de la vida recae por parte del Estado; se sugiere que esta administración implica una política del miedo y el miedo, a su vez, se convierte en el componente básico de la subjetividad actual, cuyo eje político-ideológico subvierte los axiomas fundamentales universales que -según el filósofo- van dejando en evidencia el miedo como principio movilizador fundamental (p. 56). Precisamente, es la idea de Zizek la que Eltit expone, en relación con los sujetos/habitantes de los bloques en Fuerzas Especiales como 
grupo social castrado en su subjetividad y progresivamente mutilado, como aparenta serlo para los habitantes de los bloques, cuyo corolario es: "[...] la atemorizada comunión de personas atemorizadas" (p. 56). Esta proposición, significativa para la investigación, queda en evidencia en el siguiente párrafo:

El bloque, el mío particularmente, el que yo habito, es una representación del bloque miedo, una forma gráfica que podría levantarse, hincharse, inflarse cualquier día y explotar como un tubo de gas porque la presión del miedo llegaría a niveles inmanejables y el estallido sería la única forma de consumación (Eltit, 2013, p. 89).

En la relación Estado/Poder, este binomio logra establecer una forma de dominio avasallador en contra de los habitantes del bloque. Mediante la violencia y el miedo, el Estado exhibe los efectos de una ideología cuyo propósito es legitimizar y extender el período de dominación por parte de la Superestructura de Poder. Este afán de justificación, insinuado por las anáforas de la represión, se podría leer como la táctica militar/escritural más trascendente del relato. Esta estrategia -que Eltit hace ostensible de manera paranoica- podría arrojar la siguiente lectura, que metaforiza un instructivo proveniente de un manual de guerra: "...se avanza solapadamente, con tanques y metralletas: cada veinte o treinta líneas, aparecen, como minas en un párrafo minado, las anáforas de la represión; éstas tienen un solo objetivo: liquidar al personaje/habitante $\mathrm{y}$, sin dejar rastros, amedrentar al lector, del mismo modo. No hay que dejar rastros ni huellas".

Son estas "evidencias" las que se solidifican en el inconsciente de los habitantes/personajes y del lector; desde este territorio, se desprenden los edictos que revalidan la postura estatal/militarizada que gobierna el mundo en el que se desenvuelven los personajes del libro. Es una muestra del poder destructor del Estado y que, alegóricamente, Eltit repite de manera imperturbable. La escritora, en esta distribución física de su narrativa, aludiría perspicazmente a la idea que plantea Pierre Bourdieu: "[...] todo poder que logra imponer significaciones e imponerlas como legítimas disimulando las relaciones de fuerza en que se funda su propia fuerza, añade su propia fuerza [...]" (Bourdieu, 1996, p. 44). Por tanto, el Estado -bajo la idea de Bourdieu- amplifica su poder al poderío ya existente, por medio de los significantes que Eltit despliega y anaforiza en su libro y que son cautelosamente revelados ${ }^{1}$ : "Había un rifle Taurus M62" (2013, p. 11); "Había ciento veinte Tokarev 7,62 mm" (p. 44); "Había cien cuchillos tácticos

\footnotetext{
${ }^{1}$ De hecho, el libro abre con la oración: "Había dos mil Webley-Green .455" (Eltit, 2013, p. 11), y termina del mismo modo: "Había cuatro mil millones de proyectiles de artillería teledirigidos de alto rango XM82 Excalibur" (p. 165).

26 | AlPHA No 52 (Julio 2021) PÁGS. 11-30. ISSN 07 16-4254
} 
Ontario 216-8300" (p. 59); "Había doce miras Zip 4 x 24" (p. 66); "Había cuarenta y cinco helicópteros polivalentes August-Westland AW139" (p. 90); "Había cinco mil cazas Su-30SM" (p. 99); "Había cien millones de agentes incapacitantes VZ" (pp. 141-142); "Había tres mil dispositivos de largo alcance LRAD" (p. 161). Bajo este discurso iterativo, Eltit insiste en revelar la mano invisible que castiga e intimida a los habitantes de los bloques. La escritora toma la imagen del brazo armado, y de cómo este es capaz de intimidar y hostigar al personaje/habitante de la narrativa, que subsiste amedrentado por las armas y la violencia. Este hostigamiento no buscaría como fin último la represión del sujeto, sino que tendería a la normalización del proceder de las Fuerzas Especiales: la violencia/miedo como concepto de vida tendiente a la regulación de conductas y al despojo de toda memoria y formas de representación. Esta idea alude al concepto de violencia epistémica de Spivak en donde el simbolismo que envuelve todas las conductas del sujeto se posponen ante la negación de sus propias conductas: "[...] me proyecto como Dios y me amplifico dotada de una esquirla de divinidad. Pero no soy yo, somos el yo bloque que habita genéticamente en cada uno de nosotros" (Eltit, 2013, p. 78). Más aún, esta artimaña tendería a respaldar la ideología política de Estado en cuanto a su "cuerpo político". Según Foucault, este cuerpo provee materiales, vías de comunicación y principalmente armas que buscan, como fin último, apoyar las relaciones de poder. Las relaciones que surgen de este entramado cercan los cuerpos y los dominan. (p. 35). Más aún, Foucault (2002) insiste que estas prácticas que brotan desde el "cuerpo político" buscan principalmente dirigirse al alma (p. 35).

De esta manera, lo que propone Eltit en este nivel de análisis es dar cuenta que existe un entramado político y social que castiga tanto al cuerpo como al alma del individuo. No obstante, Eltit, al desnudar estos discursos de Poder en forma de narrativa, subvierte esta idea, disparando a quemarropa hacia los engranajes -las Fuerzas Especiales- que sostienen esta ingeniería social. Esta dialéctica acuciante que propone Eltit se podría leer como aquel contradiscurso, heterogéneo, de resistencia; estoico, fustigador, tenaz y axiomático, así como lo plantea Gramsci: "Encontrar la identidad real, [...] la diferenciación y contradicción y hallar la diversidad sustancial bajo la aparente identidad, he ahí la cualidad más esencial del crítico [...]" (Gramsci, 1981, p. 99). En todo caso, este discurso es capaz de remecer los pilares de la superestructura y de la misma manera devela las incoherencias del sistema mismo: un sistema oscuro, intrincado e invisible. Como la metáfora que Foucault plantea en Vigilar y Castigar: "El acero que castiga al culpable es también el que destruye a los enemigos" (Foucault, 2002, p. 55). 


\section{CONCLUSIÓN: LA RETÓRICA DE LA REPRESIÓN}

La forma de representar la violencia y el miedo por parte de Eltit es inquietante. La autora justifica cada enunciado anclando su retórica a un discurso locuaz y paradójico. Su intrincada forma de referirse al miedo, la pobreza y la violencia, sumado al frenesí semántico de cada palabra minuciosamente escogida, desplazan los significados de la obra hacia territorios cada vez más perturbadores y oscuros, lo que trasunta en una lectura sombría y difícil de dilucidar para el lector. Así, la intención de esta investigación fue arrojar luces hacia el flujo discursivo de Eltit: se intentó descifrar las posibles lecturas de esta narrativa, en especial de la forma que la escritora/narradora representa y simboliza la dualidad de un discurso opresivo y segregador que refiere principalmente a las tácticas que son empleadas para hostigar y subyugar a los sujetos/habitantes del libro.

La manera brillante de Eltit de representar su pensamiento como forma de resistencia a la ofensiva militarizada de las Fuerzas Especiales puede ser observable en cuanto la retórica de su pluma manifiesta una fuerza semánticadiscursiva que trasciende la propia lectura de su narrativa. Las herramientas retóricas que Eltit dispone a lo largo del texto, como anáforas, metáforas, alusiones y un sinnúmero de otras figuras, son las que van dando forma a esta obra que da cuenta de una ideología letal que atraviesa en cuerpo y alma al personaje/habitante del bloque.

La retórica de la represión simboliza la forma en que el Poder despliega su dominio sin piedad en contra de una parte importante de la población. Son estas tácticas que se expresan en esta investigación -pobreza, hacinamiento y miedolas que aluden a un Sistema/Estado asesino. Para analizar esta obra, no basta con un análisis denotativo/literal de estas tácticas; por el contrario, las estratagemas reveladas en esta investigación dan cuenta de una lectura más profunda: la pobreza simbólica del lenguaje que se apodera del tenor del relato; la construcción de un discurso amotinado y segregado que hacina al personaje, pero también al lector de esta narrativa; por último, la violencia semántica de cada línea que genera discursos y contradiscursos llenos de ira.

Igualmente, se observa una complejidad discursiva que alienta un modo enrevesado y profundo de análisis. De esta manera, la intención de Eltit de representar la violencia, el hacinamiento y la pobreza en esta narrativa converge en un momento histórico consciente y determinado en donde el flujo hermenéutico de la representación misma de estos signos alcanza un punto rizomáticamente álgido; son los intersticios semióticos y los desplazamientos de significantes las piezas que permiten que la lectura vaya adquiriendo ribetes cada 
vez más sombríos. Es una propuesta osada cuyo territorio -habitado por este binomio en donde la narradora/autora pareciera fusionarse en una sola conciencia- reúne todos los elementos requeridos, con el fin de proyectar un relato violento e irascible que se esparce hacia todas direcciones. Esto, a su vez, trasunta en una cadena de significación infinita, lo que supone un camino sinuoso para el osado lector(a). De este modo, la lectura del miedo, el hacinamiento y la pobreza como fenómenos de conciencia y como fenómenos esenciales en la retórica de Eltit fomentan la deconstrucción de ambos sistemas: del Sistema/Poder que mantiene a este engranaje asesino y del mismo sistema de significación que sostiene la retórica de Fuerzas Especiales.

Las dos conclusiones más importantes de este estudio son, primero, que no hay, creo, un sistema de signos que pueda decodificar los símbolos de Fuerzas Especiales, ya que la autora, en la exégesis misma de su relato, desea que su retórica hable por sí misma ${ }^{2}$; y segundo, que Eltit, en el detrimento social que proyecta su narrativa, intenta desesperadamente establecer una voz potente que genera una resistencia y pone en la palestra la dicotomía de un discurso social consumista/capitalista versus una realidad poblacional que lo prohíbe y posterga.

\section{OBRAS CITADAS}

Althusser, Louis (1988). Ideología y aparatos ideológicos de Estado. Buenos Aires: Ediciones Nueva Visión.

Bourdieu, Pierre y Passeron, Jean-Claude (1996). La reproducción. Elementos para una teoría del sistema de enseñanza. Mexico: Fontamara.

Castells, Manuel (2004). La cuestión urbana. México: Siglo XXI.

Deleuze, Gilles y Guattari, Félix (1985). El Anti-Edipo: Capitalismo y esquizofrenia. Barcelona: Paidós Ibérica.

Derrida, Jacques (1989). La escritura y la diferencia. Barcelona: Anthropos.

Eltit, Damiela (2013). Fuerzas Especiales. Santiago: Planeta.

Etchepare, Jaime (2018). La derecha chilena, principales vertientes ideológicas, partidismo y evolución electoral. Disponible en: http://www.archivochile.com/ (Rescatado el 11 de agosto de 2018).

Foucault, Michel (2010). Las palabras y las cosas. Buenos Aires: Siglo XXI — (2002). Vigilar y castigar. Buenos Aires: Siglo XXI.

Gómez Leyton, Juan (2018). Las poblaciones callampas. Disponible en: www.flacsochile.org (Rescatado el 25 septiembre de 2018).

\footnotetext{
2 Lo que Foucault denomina en Las Palabras y las Cosas: “[...] el poder propio de la representación de representarse a sí misma" (2010, p. 83).
} 
Gramsci, Antonio (1981). Cuadernos desde la cárcel. México: Ediciones Era.

Kierkegaard, Soren (2007). El concepto de la angustia. Madrid: Alianza.

Larrañaga, Osvaldo y Rodríguez, María Eugenia (2018). Desigualdad de Ingresos y Pobreza en Chile 1990 a 2013. Disponible en: www.undp.org (Rescatado el 31 de diciembre de 2018).

Marcuse, Herbert (1968). El hombre unidimensional. Ensayos sobre la ideología de la sociedad industrial avanzada. México: Joaquín Mortiz.

Mayol, Alberto (2003). "La tecnocracia: el falso profeta de la modernidad". Revista de sociología $\mathrm{N}^{\circ} 17: 95-123$.

Portillo, Álvaro (2002). Otro Estado es posible. Barcelona: Icaria.

Rubio, Pablo (2018). La derecha política chilena y el régimen militar: entre la independencia y la subordinación, 1973-1990. Disponible en: www.dialnet.unirioja.es (Rescatado el 20 de diciembre de 2018)

Sartre, Jean Paul (2005). El ser y la nada. Buenos Aires: Losada.

Zizek, Slavoj (2009). Sobre la violencia. Seis reflexiones marginales. Barcelona: Paidós. 